\title{
Multiple slip effects on inclined MHD Casson fluid flow over a permeable stretching surface and a melting surface
}

\author{
Shalini Jain, Amit Parmar* \\ Department of Mathematics and Statistics, Manipal University Jaipur, Rajasthan 302026, India
}

Corresponding Author Email: Amit.198631@gmail.com

https://doi.org/10.18280/ijht.360222

Received: 10 August 2017

Accepted: 14 May 2018

\section{Keywords:}

non-linear radiation, non-linear heat source, melting surface, permeable surface, Casson fluid

\begin{abstract}
In this paper, we have investigated the effects of multiple slip on inclined MHD Casson fluid flow over a permeable stretching surface and a melting surface. We have considered first and second order velocity slip, non-linear radiation, non-uniform heat source and non-linear chemical reaction. The analysis is carried out numerically for the momentum, heat and mass equations by solving the bvp4c MATLAB solver. The physical features of non-dimensional Casson fluid parameter, Schmidt number, Eckert number, variable radiation parameter, porosity parameter, variable heat source parameter, Prandtl number, Skin friction coefficient, local Nusselt number and local Sherwood number of velocity, temperature, volume fraction have been discussed and depicted by the graphs and tables. The $\theta$ and $\phi$ profiles were uplifted with the increment of the $\beta, \mathrm{M}$ and Kp parameters on a suction and melting surface whereas the opposite behavior observed on $f^{\prime}$ profiles and the $f^{\prime}$ 'profile and momentum boundary layer thickness was depressed with the increment of the $L_{1}$ and $L_{2}$ parameters under a suction and a melting surface whereas the reverse behavior observed on $\theta$ and $\phi$ profiles. The impact of various physical parameters of melting surface and porous surface are obtained and observed that the effect of melting surface is higher than porous surface.
\end{abstract}

\section{INTRODUCTION}

The MHD boundary layer flow over a porous stretching surface have many applications in manufacturing processes, plasma studies, petroleum industries, MHD power generator, boundary layer control in aerodynamics, chilling of nuclear reactors, crystal fiber production and paper production. Many theoretical and experimental investigations have examined several researchers. Animasaun [1] investigated MHD Casson fluid flow with suction and non-linear chemical reaction. Megaheda [2] studied MHD Casson fluid over a permeable stretching sheet. Several researchers [3-19] proposed the nonNewtonina and Newtonian fluid for various surfaces and studied the various parameter effects

The non-Newtonian fluid flow is a fundamental process, not only in the geophysics area, i.e. Lava flows and mud floods, but also in a variety of industrial applications. It is frequently encountered in biomedical engineering, material processing, food and chemical industry. Non-Newtonian Casson fluid such as blood and permeable surface like arteries so nonNewtonian Casson fluid superposed to the flow at the permeable arteries of the human body and help of various critical diseases salvage. Casson fluid behave

es like an elastic solid fluid. It exhibits shear thinning characteristics, high shear viscosity and yield stress. Several researchers investigated for Casson fluid over different surface Sandeep et al. [20], Bhattacharyya et al. [21-22], Mukhopadhyay [22], Animasaun et al. [24-25]. Hayat et al. [26-27] investigated 2D and 3D MHD Casson fluid in porous medium. All the above studies deal with the flow and heat transfer over a stretching surface for a Newtonian fluid and non-Newtonian fluid flow under different thermal boundary conditions and various slip condition. Following research scholar, Rajani et al. [44], Rahman et al. [45], Mallikarjuna et al. [46], Sharma et al. [47] and Arifuzzaman et al. [48] investigate the higher order chemical reaction for various fluids. Raju et al. [49-50], Madaki et al. [51] Sivakumar et al. [52] investigation on different boundary condition with different fluid over different surfaces.

In this article, we have investigated flow over the two different boundary surface a melting surface and a porous surface for inclined MHD Casson fluid flow with higher order chemical reaction, variable radiation and heat source. We also considered the first and second order velocity slip, temperature slip and mass slip.

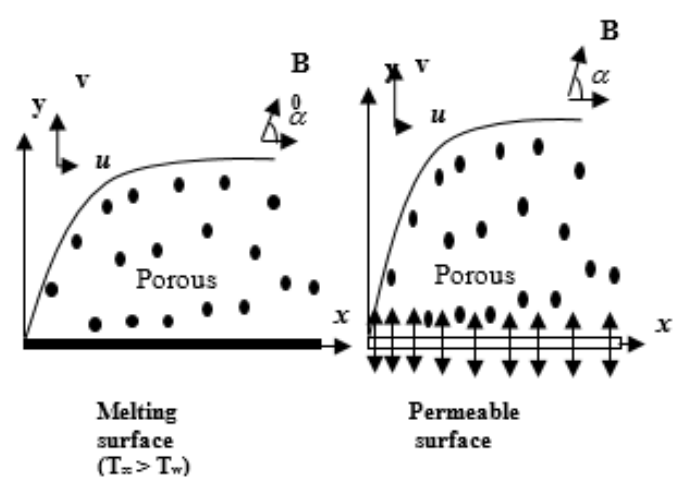

Figure 1. Physical diagram of the problem 


\section{MATHEMATICAL FORMULATION}

Consider two-dimensional steady incompressible inclined MHD Casson fluid flow over a two different surface such as a permeable surface and a melting surface with first and second order velocity slip, non-linear radiation, non-uniform heat source and non-linear chemical reaction. Let surface is stretching is along the $\mathrm{x}$ axis with stretching velocity $b x$.

The continuity, velocity, heat and mass equations are given by

$\frac{\partial u}{\partial x}+\frac{\partial v}{\partial y}=0$

$u \frac{\partial u}{\partial x}+v \frac{\partial u}{\partial y}=v\left(1+\frac{1}{\beta}\right) \frac{\partial^{2} u}{\partial y^{2}}-\left(\frac{\sigma B_{0}^{2} \sin ^{2} \alpha}{\rho}+\frac{v}{k_{p}}\right) u$

$u \frac{\partial T}{\partial x}+v \frac{\partial T}{\partial y}=\frac{k}{\rho C_{p}} \frac{\partial^{2} T}{\partial y^{2}}-\frac{1}{\rho C_{p}} \frac{\partial q_{r}}{\partial y}+\frac{\sigma B_{0}^{2} \sin ^{2} \alpha}{\rho C_{p}} u^{2}+\frac{q^{\prime \prime \prime}}{\rho C_{p}}$

$u \frac{\partial C}{\partial x}+v \frac{\partial C}{\partial y}=D_{m} \frac{\partial^{2} C}{\partial y^{2}}-k_{n}\left(C-C_{\infty}\right)^{n}$

where $u(x, y)$ and $v(x, y)$ are the horizontal and vertical velocity components, $\rho$ : fluid density, $v$ : kinematic viscosity, $\rho \mathrm{C}_{\mathrm{p}}$ : particles heat capacities. T: fluid temperature, $T_{\infty}$ : ambient fluid temperature, $b$ : positive constant.

Subject to the following boundary conditions:

For porous surface (refs [2] and [20])

$u=u_{w}+\left(1+\frac{1}{\beta}\right)\left(a_{1} \frac{\partial u}{\partial y}+a_{2} \frac{\partial^{2} u}{\partial y^{2}}\right), v=-v_{w}, T=T_{w}+b_{1} \frac{\partial T}{\partial y}$,

$C=C_{w}+b_{2} \frac{\partial C}{\partial y} \quad$ at $y=0$

$u \rightarrow 0, T \rightarrow T_{\infty}, C \rightarrow C_{\infty} \quad$ at $y \rightarrow \infty$

For melting surface [31-33]

$u=u_{w}+\left(1+\frac{1}{\beta}\right)\left(a_{1} \frac{\partial u}{\partial y}+a_{2} \frac{\partial^{2} u}{\partial y^{2}}\right), T=T_{w}+b_{1} \frac{\partial T}{\partial y}$

$v=k \frac{1}{\left(\rho\left[\beta_{m}+c_{s}\left(\mathrm{~T}_{w}-\mathrm{T}_{0}\right)\right]\right)} \frac{\partial T}{\partial y}, C=C_{w}+b_{2} \frac{\partial C}{\partial y}$ at $y=0$

$u \rightarrow 0, T \rightarrow T_{\infty}, C \rightarrow C_{\infty}$

at $y \rightarrow \infty$

$u_{w}=b x:$ stretching velocity, $v_{w}:$ suction/injection velocity. $q^{\prime \prime \prime}:$ non-uniform heat source [43]

$q^{\prime \prime}=\frac{k u_{s}(x, t)}{x v}\left[A^{*}\left(T_{w}-T_{\infty}\right) f^{\prime}+B^{*}\left(T-T_{\infty}\right)\right]$ in which A* and $\mathrm{B}^{*}$ : Space and temperature dependent heat source coefficients, respectively. Following Rosseland approximation $q_{r}$ is given as

$q_{r}=-\left(\frac{4 \sigma}{3 k^{*}}\right) \frac{\partial T^{4}}{\partial y}=-\left(\frac{16 \sigma}{3 k^{*}}\right) T^{3} \frac{\partial T}{\partial y}$

\section{Solution}

We introduce the following relations for $u, v$

$u=b x f^{\prime}(\eta), \quad v=-\sqrt{b v} f(\eta), \quad \eta=y \sqrt{\frac{b}{v}}$

$\phi(\eta)=\frac{C-C_{\infty}}{C_{w}-C_{\infty}}$ and $\theta(\eta)=\frac{T-T_{\infty}}{T_{w}-T_{\infty}}$

Equation (2) to (4) thus reduces to the following nondimensional form

$\left(1+\frac{1}{\beta}\right) f^{\prime \prime \prime}-f^{\prime 2}+f^{\prime \prime} f-M \sin ^{2} \alpha f^{\prime}-\mathrm{K}_{p} f^{\prime}=0$

$\theta^{\prime \prime}+A^{*} f^{\prime}+B * \theta+\operatorname{Pr}\left(E c M \sin ^{2} \alpha f^{\prime 2}+f \theta^{\prime}\right)+$

$\frac{4}{3} R\left[((\varepsilon-1) \theta+1)^{3} \theta^{\prime \prime}+3((\varepsilon-1) \theta+1)^{2} \theta^{\prime 2}\right]=0$

$\phi^{\prime \prime}-S c\left(K_{n} \phi^{n}-f \phi^{\prime}\right)=0$

Boundary conditions (5) reduces as:

For porous surface-

$\eta=0: \quad f^{\prime}(\eta)=1+\left(1+\frac{1}{\beta}\right)\left(L_{1} f^{\prime \prime}(\eta)+\mathrm{L}_{2} f^{\prime \prime}(\eta)\right)$,

$f(\eta)=S, \theta(\eta)=1+\delta_{1} \theta^{\prime}(\eta), \phi(\eta)=1+\delta_{2} \phi^{\prime}(\eta)$,

$\eta \rightarrow \infty: \quad f^{\prime}(\eta) \rightarrow 0, \theta(\eta) \rightarrow 0, \phi(\eta) \rightarrow 0$

For Melting surface-

$\eta=0: \quad f^{\prime}(\eta)=1+\left(1+\frac{1}{\beta}\right)\left(L_{1} f^{\prime \prime}(\eta)+\mathrm{L}_{2} f^{\prime \prime}(\eta)\right)$,

$f(\eta)=-\frac{M e}{\operatorname{Pr}} \theta^{\prime}(\eta), \theta(\eta)=1+\delta_{1} \theta^{\prime}(\eta)$,

$\phi(\eta)=1+\delta_{2} \phi^{\prime}(\eta)$,

$\eta \rightarrow \infty: \quad f^{\prime}(\eta) \rightarrow 0, \theta(\eta) \rightarrow 0, \phi(\eta) \rightarrow 0$

where $L_{1}=a_{1} \sqrt{\frac{b}{v}}$ : first order velocity slip parameter, $L_{2}=a_{2} \frac{b}{v}$ : second order velocity slip parameter, $\delta_{1}=b_{1} \sqrt{\frac{b}{v}}$ : temperature slip parameter, $\delta_{2}=b_{2} \sqrt{\frac{b}{v}}$ : concentration slip parameter, $\operatorname{Pr}=\frac{k}{\mu C_{p}}$; Prandtl number, $R=\frac{4 \sigma T_{\infty}^{3}}{k k^{*}}$; radiation parameter, $k^{*} ;$ thermal radiation parameter, $E c=U^{2} / C_{p}\left(T_{W}-T_{\infty}\right) ;$ Eckert number, $M=\frac{\sigma B_{0}^{2}}{\rho b}$ : magnetic field parameter, $\beta$ : Casson fluid parameter $S c=\frac{v}{D_{m}}$; 
Schmidt number, $C_{s}$ : the heat capacity of the solid surface $K_{n}=\frac{k_{n}}{b}\left(C_{w}-C_{\infty}\right)^{n-1}:$ chemical reaction parameter, $\beta_{m}$ : the latent heat of the fluid, $\varepsilon=\frac{T_{w}}{T_{\infty}}:$ temperature difference parameter, $k:$ thermal conductivity $K p=\frac{v}{k_{p} b}$ : porosity parameter, $M e=\frac{\left(T_{w}-T_{\infty}\right) \mathrm{c}_{p}}{\left(\beta_{m}+\mathrm{c}_{s}\left(T_{m}-T_{0}\right)\right)}:$ dimensionless melting parameter, temperature of the melting surface where $T_{\infty}>T_{m}$.

The cofficient of skin friction $C_{f}$, local Nusselt number $N u_{x}$ and local Sherwood number $S h_{x}$ are defined as:

$C_{f}=\left(1+\frac{1}{\beta}\right) \frac{\tau_{w}}{\rho U^{2}}, N u_{x}=\frac{x q_{w}}{k_{\infty}\left(T_{w}-T_{\infty}\right)}$, and

$S h_{x}=\frac{x J_{w}}{D_{B}\left(C_{w}-C_{\infty}\right)}$

where the skin friction $\tau_{w}$, the heat flux $q_{w}$ and surface mass flux on the sheet are

$$
\begin{gathered}
\tau_{w}=\mu\left(\frac{\partial u}{\partial y}\right)_{y=0} \& \quad q_{w}=\left(-k \frac{\partial T}{\partial y}+q_{r}\right)_{y=0}=-\left(1+\frac{4}{3} \mathrm{R} \varepsilon^{3}\right) \theta^{\prime} \\
J_{w}=-D_{B}\left(\frac{\partial C}{\partial y}\right)_{y=0} ;
\end{gathered}
$$

The dimensionless expressions for $C_{f}, N u_{x}$ and $S h_{x}$ are given as following.

$$
\begin{aligned}
& c_{f} \operatorname{Re}_{x}^{\frac{1}{2}}=\left(1+\frac{1}{\beta}\right) f^{\prime \prime}(0), \\
& N u \operatorname{Re}_{x}^{-\frac{1}{2}}=-\left(1+\frac{4}{3} R \varepsilon^{3}\right) \theta^{\prime}(0), \text { and } S h / \sqrt{\operatorname{Re}}=-\phi^{\prime}(0),
\end{aligned}
$$

$C_{f}$ : skin friction coefficient, $N u_{x} \operatorname{Re}^{-1 / 2}:$ local Nusselt number and $S h_{x} \operatorname{Re}^{-1 / 2}$ : local Sherwood number.

\section{RESULTS AND DISCUSSION}

The fix value of physical parameters $L_{1}=0.2, L_{2}=-0.2$, $\mathrm{S}=0.5, \mathrm{Me}=0.5, \mathrm{R}=1, \mathrm{Pr}=2, \mathrm{M}=1, \mathrm{Kp}=0.5, \mathrm{n}=3, \mathrm{Sc}=2.0$, $\beta=2.0, \delta_{1}=\delta_{2}=0.1, \quad \alpha=\pi / 4, \theta_{w}=0.2, \quad A^{*}=0.2$, $B^{*}=0.1, \mathrm{Kn}=0.2, \mathrm{Ec}=0.2$, and excluding the varied value of particular graph. Several sets of numerical solutions have been carried out for different combinations of pertinent parameters namely, radiation parameter $(\mathrm{R})$, chemical reaction parameter $(\mathrm{Kn})$, Casson fluid parameter $(\beta)$, magnetic field parameter (M), Eckert number (Ec), suction/injection parameter (S). Figs (1-3) depicts that an increment in the value of $\mathrm{M}$, suppresses the $f^{\prime}$ profile whereas rises the $\theta$ and $\phi$ profiles. Physically, a transverse magnetic field has produced a drug-like force known as the Lorentz force which opposes the flow, causing a flow retardation effect therefore suppresses the $f^{\prime}$ profile and rises the $\theta$ profile. Figs (4) shows that $\theta$ profile enhancement as $\mathrm{R}$ increases. Generally, increasing values of $\mathrm{R}$ decreases absorption coefficient, as a result fluid temperature rises. Figs (5-7) shows that an increment in Kp suppresses the $f$ ' profile whereas enhances the $\theta$ and $\phi$ profiles. Figs (8-13) shows the influence of $\beta$ and $\alpha$ on $f^{\prime}, \theta$ and $\phi$ profiles. Increases the $\beta$ and $\alpha$ reduces the $f^{\prime}$ whereas rises $\theta$ and $\phi$ profiles. Fig (14-15) shows the impact of $A^{*}$ and $\theta_{w}$ on $\theta$ profile. Increases the value of $A^{*}$ and $\theta_{w}$ enhances $\theta$ profile. Fig (16-17) shows the influence of Sc and Kn on $\phi$ profile. Rising the Sc and Kn reduces the $\phi$ profile. Figs (18-20) shows the influence of $L_{1}$ on $f^{\prime}, \theta$ and $\phi$ profiles. An increment in $L_{1}$ suppresses the $f^{\prime}$ profile whereas rises the $\theta$ and $\phi$ profiles. Fig (21) shows the impression of $\delta_{1}$ on $\theta$ profile. An increment in the value $\delta_{1}$ reduces $\theta$ profile. Fig (21) shows the impression of $\delta_{2}$ on $\phi$ profile. An increment in the value $\delta_{2}$ reduces $\phi$ profile. Figs (23-24) shows that an increment in the $M e$ suppress $\theta$ and $\phi$ profiles. Fig (25) depicts that an increment in the value of Ec rises the $\theta$ profile. Physically, rising the values of the Eckert number than generating energy in the fluid. Figs (26-28) shows that an increment in $\mathrm{S}$ reduces $f^{\prime}, \theta$ and $\phi$ profiles. Figs (29-31) depicts that an increment in $L_{2}$ rireducing $f^{\prime}$ profile whereas reduces $\theta$ and $\phi$ profiles. Fig (32) shows that the increment in the Prandtl number increases than suppresses the $\theta$ profile.

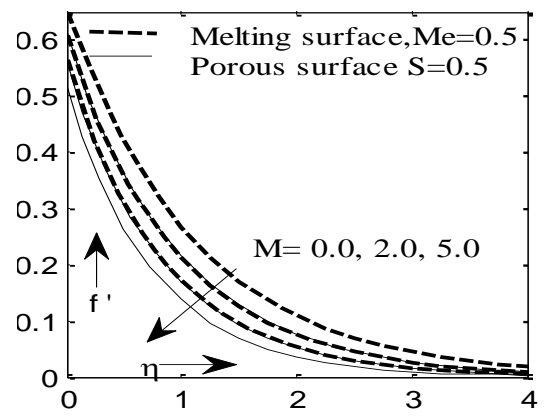

Figure 1. Influence of $\mathrm{M}$ on $f^{\prime}$

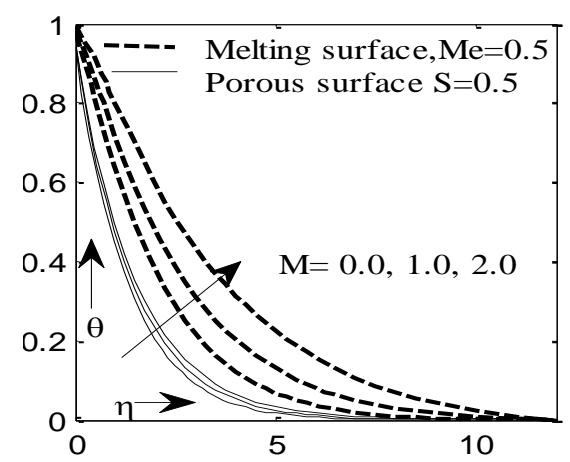

Figure 2. Influence of $\mathrm{M}$ on $\theta$ 


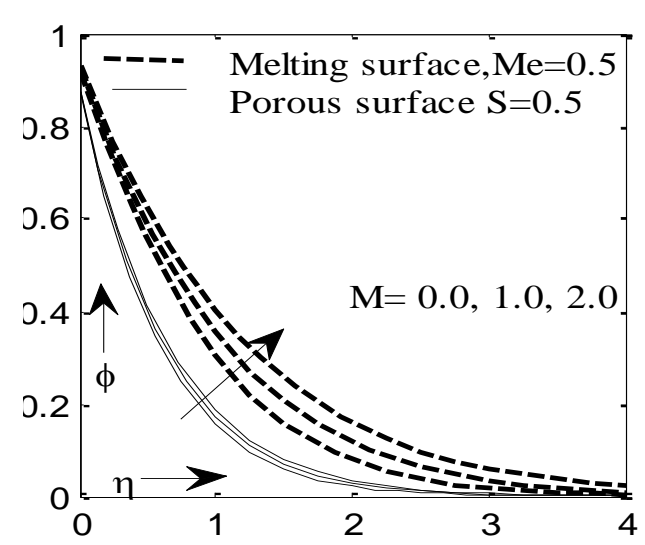

Figure 3. Influence of $\mathrm{M}$ on $\phi$

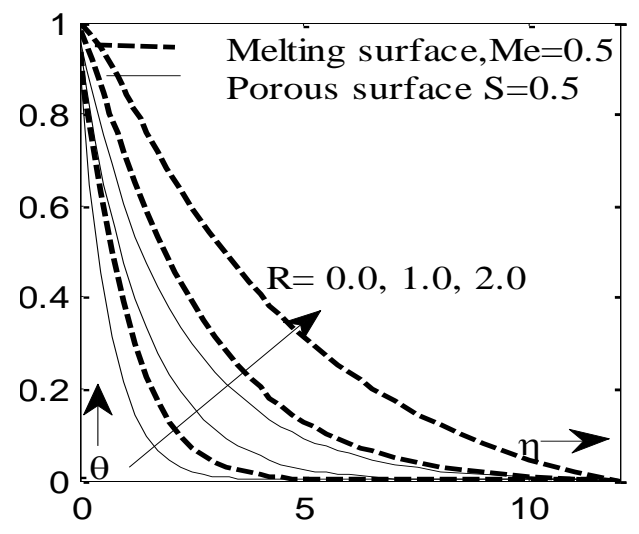

Figure 4. Influence of $\mathrm{R}$ on $\theta$

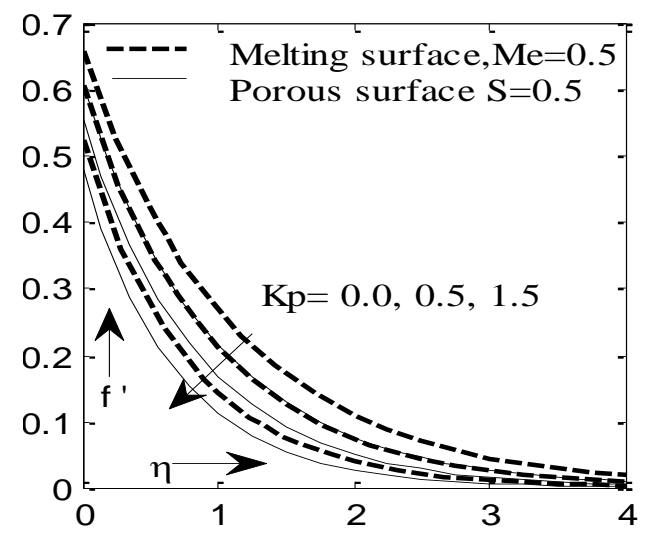

Figure 5. Influence of Kp on $f^{\prime}$

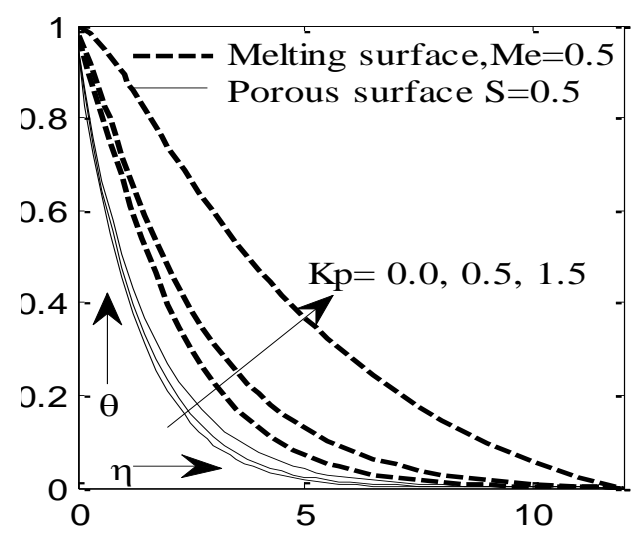

Figure 6. Influence of $\mathrm{Kp}$ on $\theta$

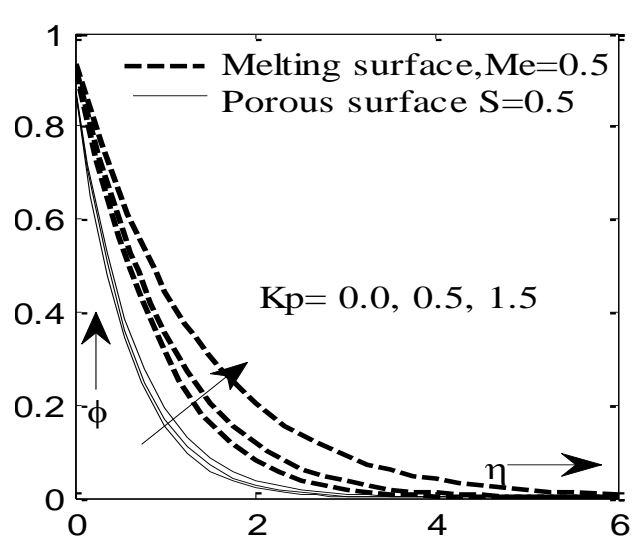

Figure 7. Influence of Kp on $\phi$

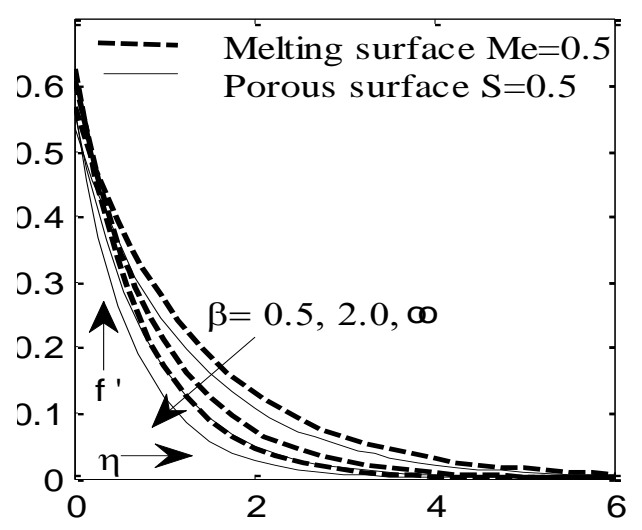

Figure 8. Influence of $\beta$ on $f^{\prime}$

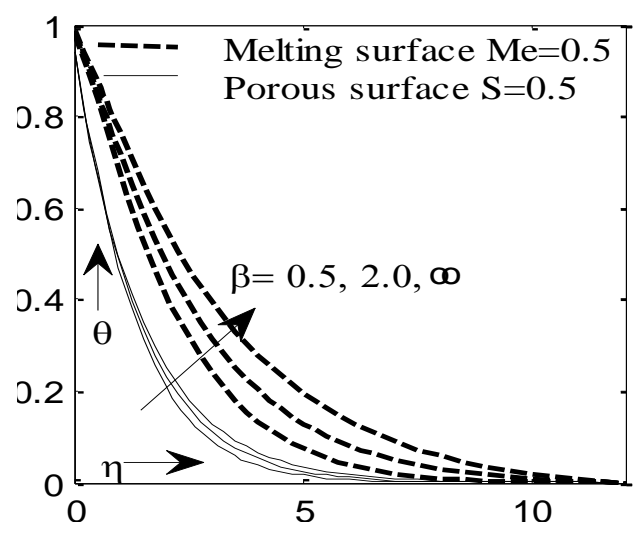

Figure 9. Influence of $\beta$ on $\theta$

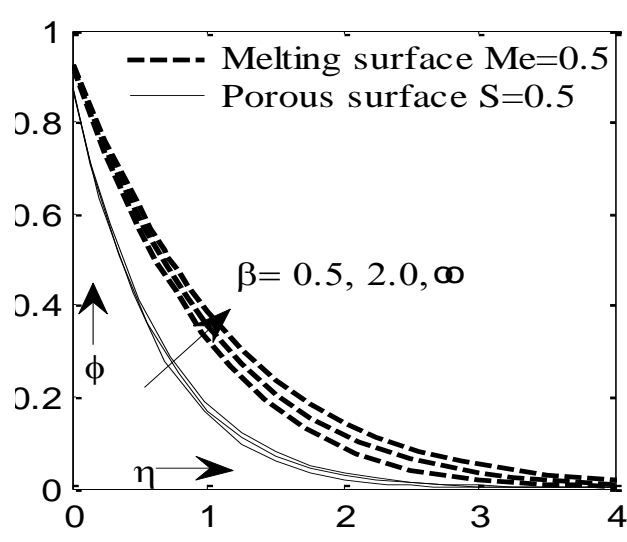

Figure 10. Influence of $\beta$ on $\phi$ 


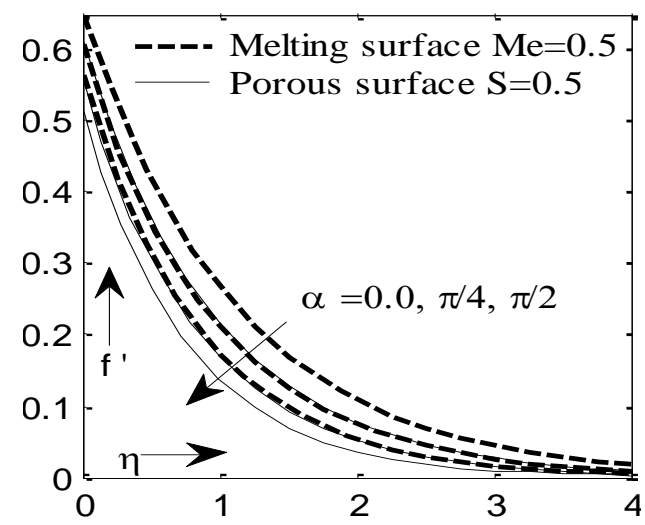

Figure 11. Influence of $\alpha$ on $f^{\prime}$

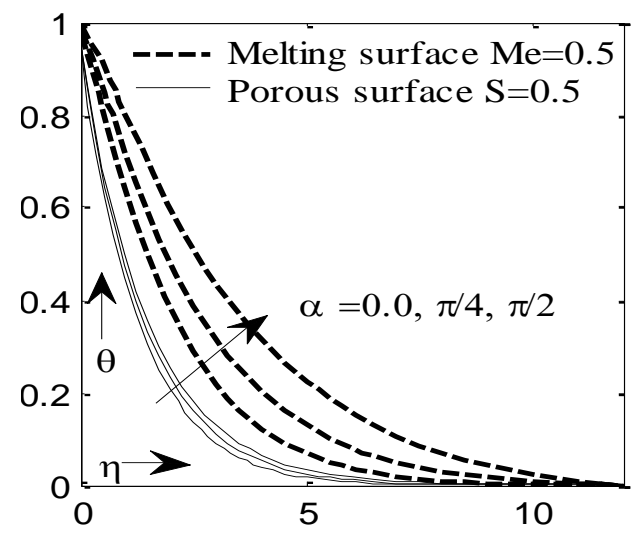

Figure 12. Influence of $\alpha$ on $\theta$

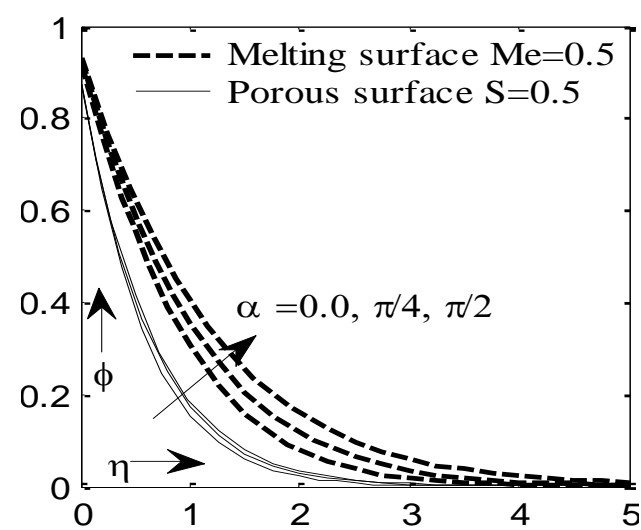

Figure 13. Influence of $\alpha$ on $\phi$

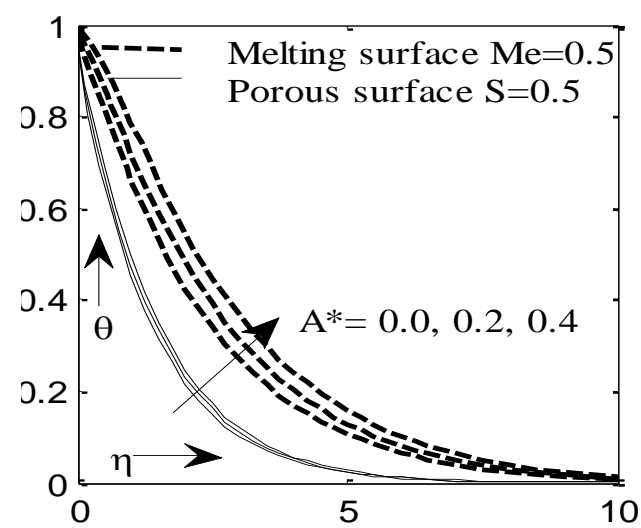

Figure 14. Influence of $A^{*}$ on $\theta$

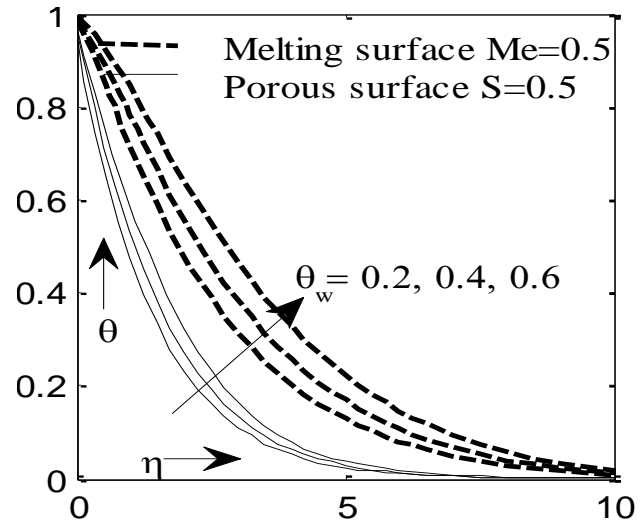

Figure 15. Influence of $\theta_{\mathrm{w}}$ on $\theta$

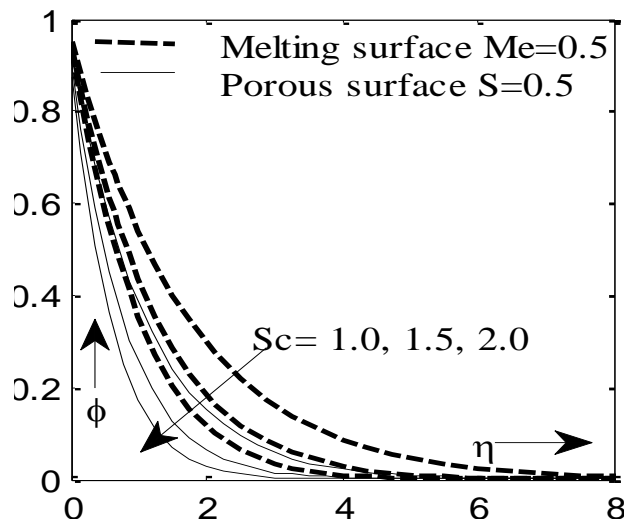

Figure 16. Influence of Sc $\phi$

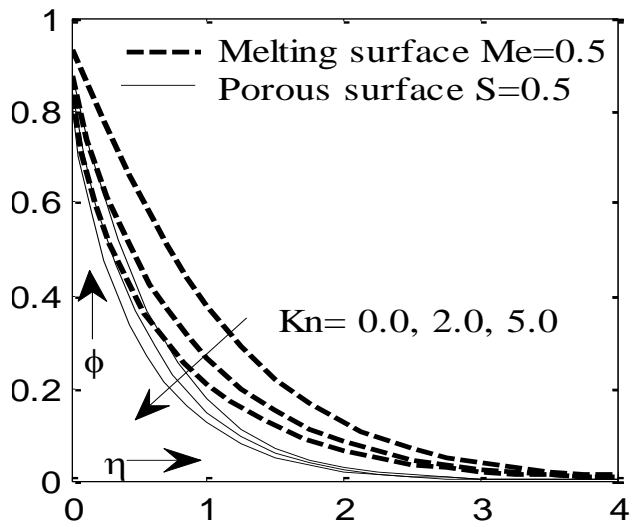

Figure 17. Influence of $\mathrm{Kn}$ on $\phi$

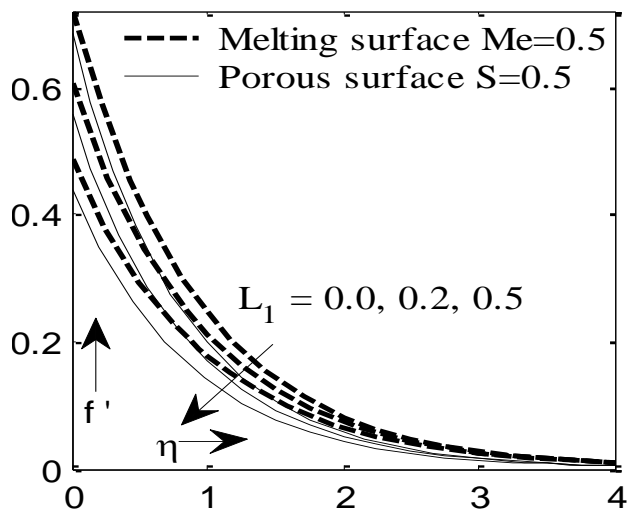

Figure 18. Influence of first $\mathrm{L}_{1}$ on $f^{\prime}$ 


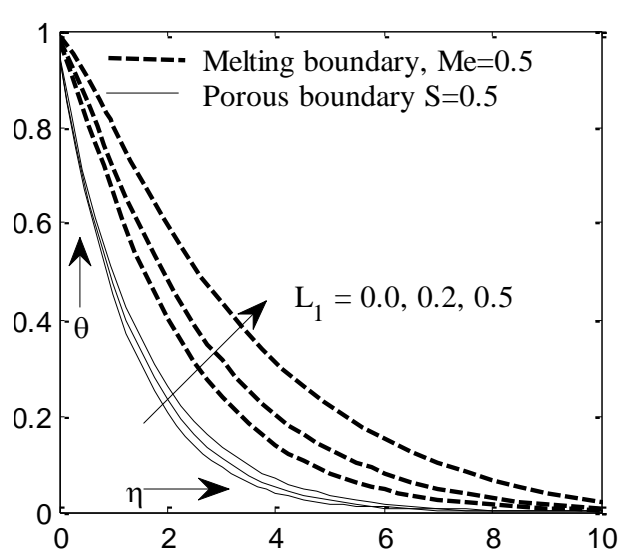

Figure 19. Influence of first $\mathrm{L}_{1}$ on $\theta$

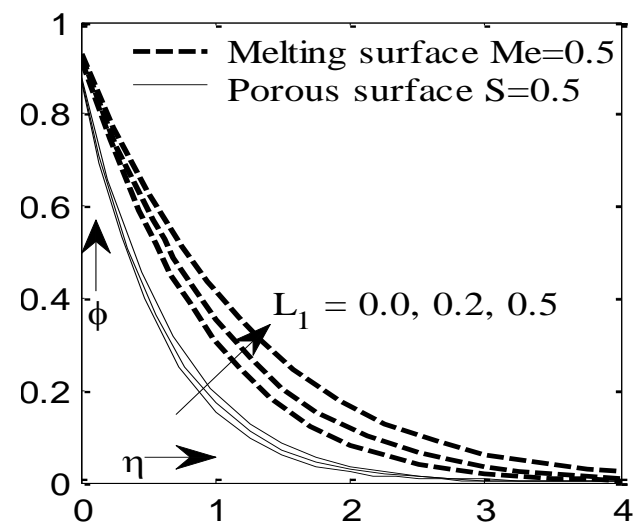

Figure 20. Influence of first $\mathrm{L}_{1}$ on $\phi$

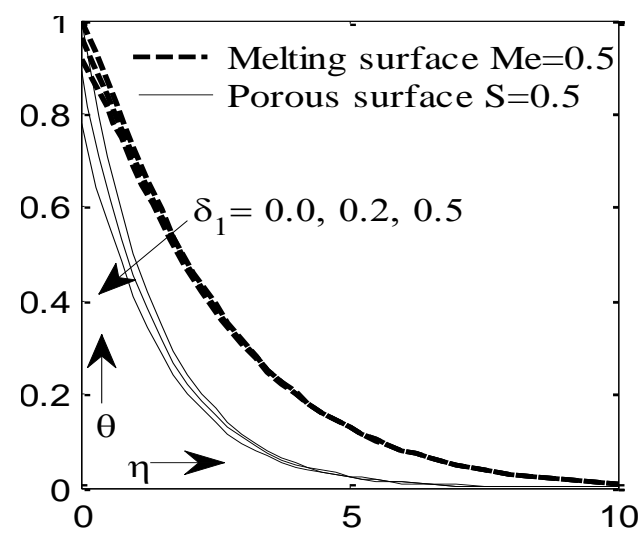

Figure 21. Influence of $\delta_{1}$ on $\theta$

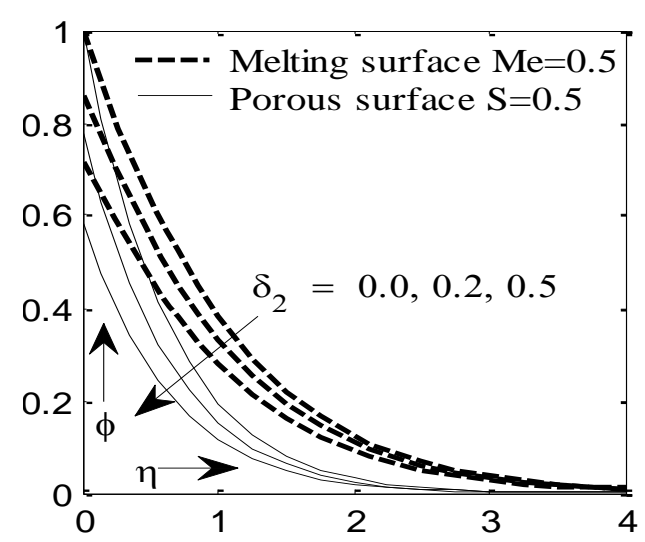

Figure 22. Influence of $\delta_{2}$ on $\phi$

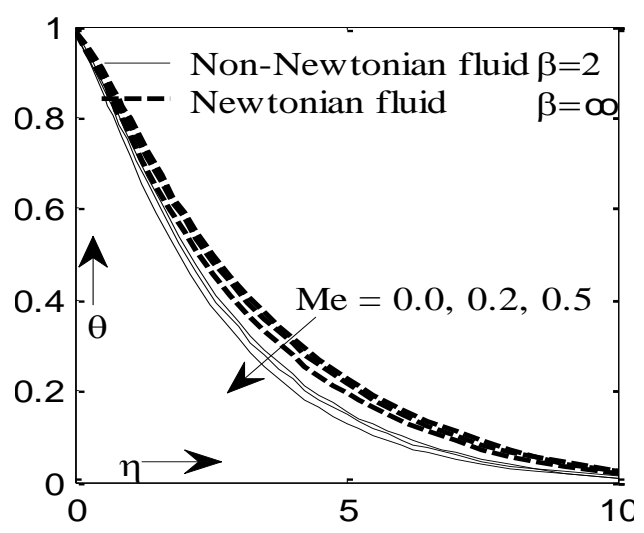

Figure 23. Influence of Me on $\theta$

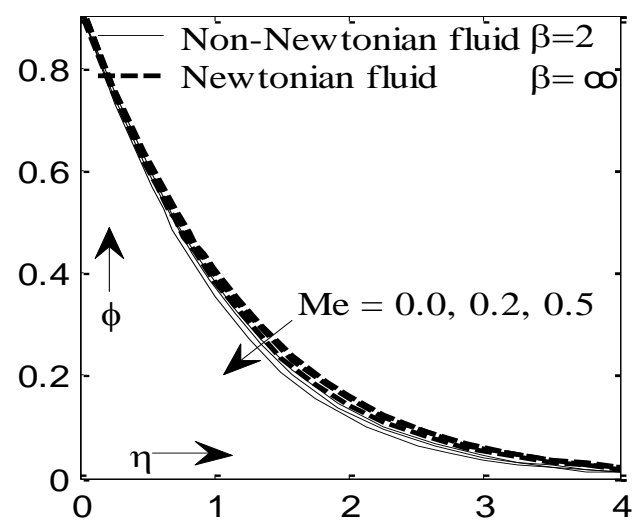

Figure 24. Influence of Me on $\phi$

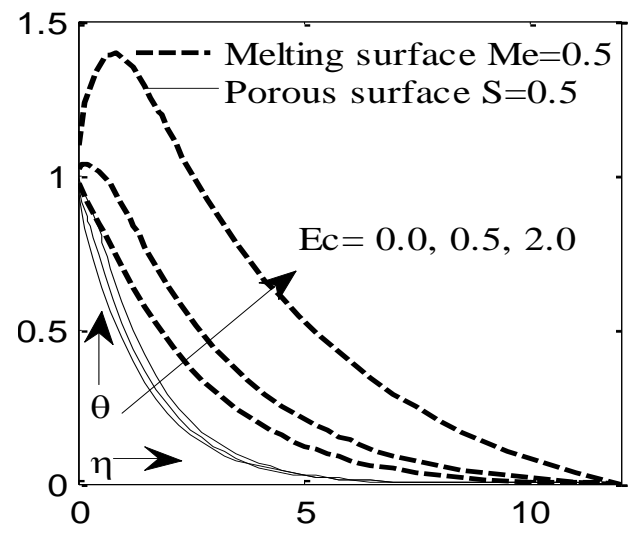

Figure 25. Influence of Ec on $\theta$

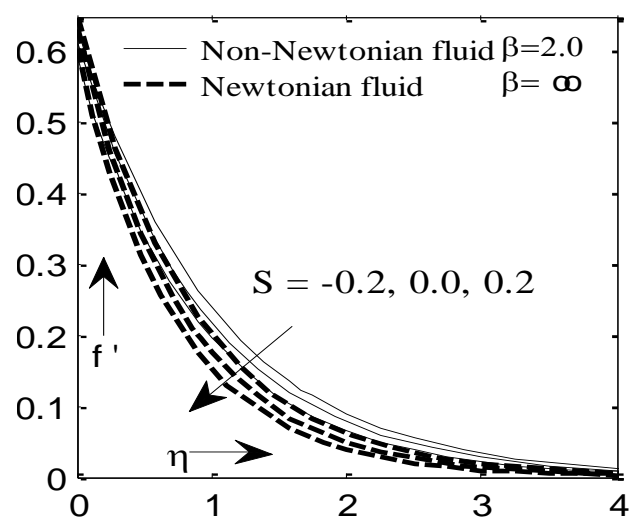

Figure 26. Influence of S on $f^{\prime}$ 


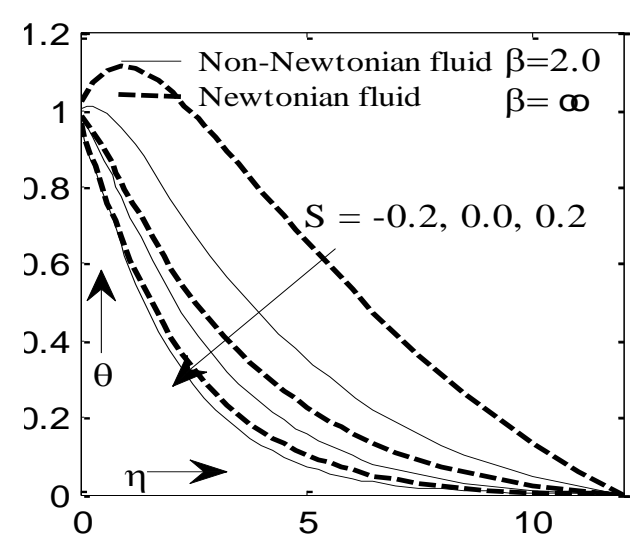

Figure 27. Influence of S on $\theta$

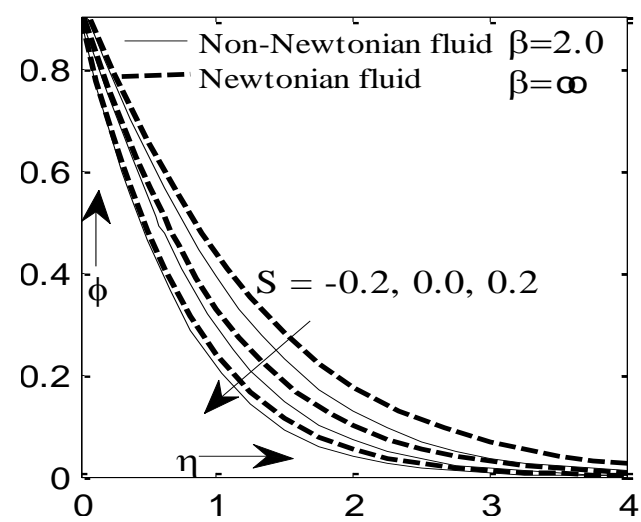

Figure 28. Influence of S on $\phi$

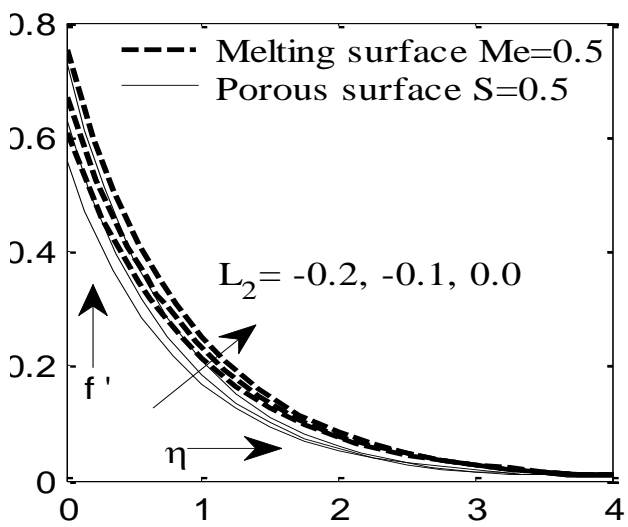

Figure 29. Influence of $\mathrm{L}_{2}$ on $f^{\prime}$

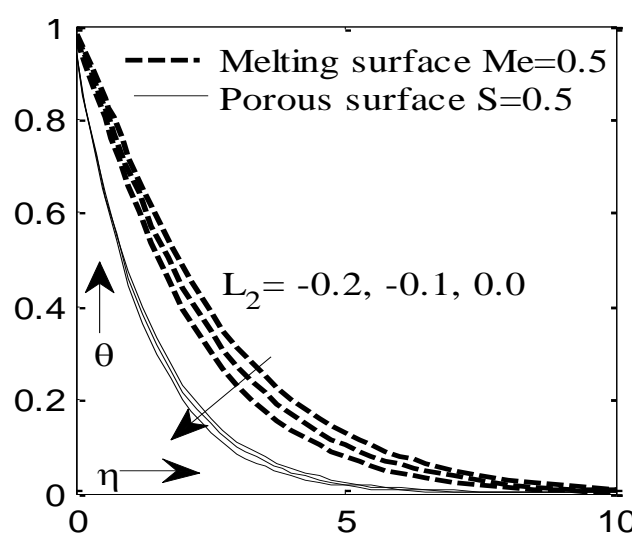

Figure 30. Influence of $\mathrm{L}_{2}$ on $\theta$

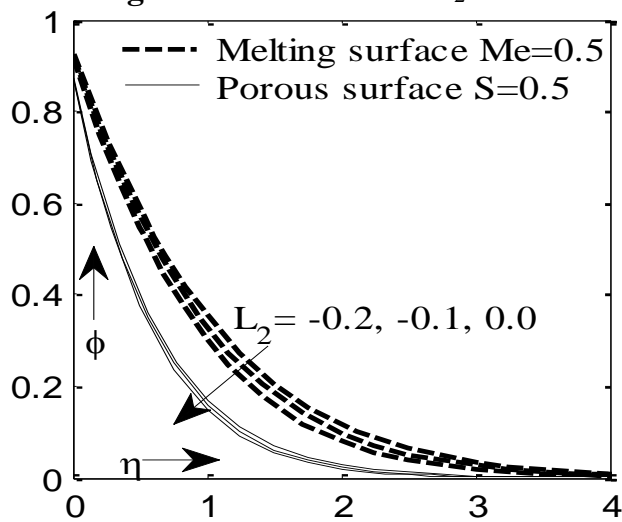

Figure 31. Influence of $\mathrm{L}_{2}$ on $\phi$

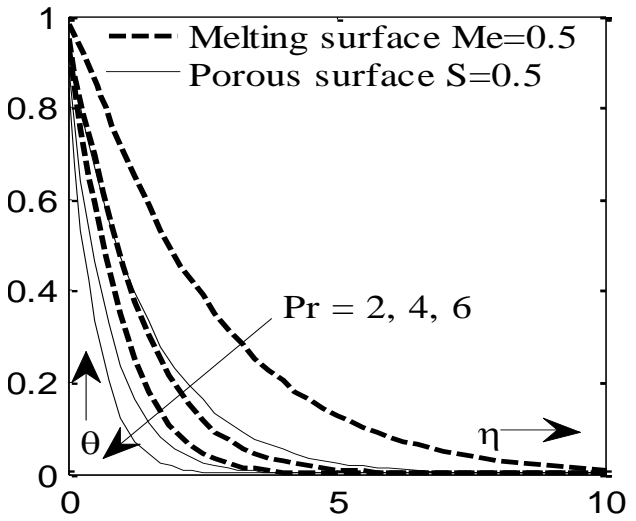

Figure 32. Influence of $\operatorname{Pr}$ on $\theta$

Table 1. Permeable surface

\begin{tabular}{|c|c|c|c|c|c|}
\hline M & $\mathrm{Kp}$ & & \multirow{2}{*}{$\left(1+\frac{1}{\beta}\right) f^{\prime \prime}$} & \multirow{2}{*}{$-\left(1+\frac{4 R}{3} \varepsilon^{3}\right) \theta^{\prime}$} & \multirow[t]{2}{*}{$\phi^{\prime}$} \\
\hline$S=0.5$ & $\mathrm{~S}=0.5$ & $\mathrm{~S}=0.5$ & & & \\
\hline 0 & & & -0.954366 & 0.6539853 & 1.314 \\
\hline 1 & & & -1.004311 & 0.6117348 & 1.279 \\
\hline \multirow[t]{7}{*}{2} & & & -1.035326 & 0.5806064 & 1.250 \\
\hline & 0 & & -0.954366 & 0.6299404 & 1.314 \\
\hline & 1 & & -1.035326 & 0.5955700 & 1.250 \\
\hline & 2 & & -1.066084 & 0.5685251 & 1.206 \\
\hline & & 0 & -0.954366 & 0.6539853 & 1.314 \\
\hline & & & -1.004311 & 0.6117348 & 1.279 \\
\hline & & & -1.035326 & 0.5806064 & 1.250 \\
\hline \multicolumn{6}{|c|}{ Melting surface } \\
\hline $\mathrm{M}$ & $\mathrm{Kp}$ & & \multirow{2}{*}{$\left(1+\frac{1}{\beta}\right) f^{\prime \prime}$} & \multirow{2}{*}{$-\left(1+\frac{4 R}{3} \varepsilon^{3}\right) \theta^{\prime}$} & \multirow[t]{2}{*}{$\phi^{\prime}$} \\
\hline $\begin{array}{c}\mathrm{Me} \\
=0.5\end{array}$ & $\begin{array}{c}\mathrm{Me} \\
=0.5\end{array}$ & $\begin{array}{c}\mathrm{Me} \\
=0.5\end{array}$ & & & \\
\hline
\end{tabular}




\begin{tabular}{|l|l|l|l|l|l|}
\hline 0 & & & -0.89438 & 0.3004638 & 0.843 \\
\hline 1 & & & -0.95763 & 0.1998305 & 0.767 \\
\hline 2 & & & -0.99936 & 0.0988653 & 0.700 \\
\hline & 0 & & -0.89272 & 0.2553512 & 0.831 \\
\hline & 1 & & -1.00007 & 0.1323109 & 0.708 \\
\hline & 2 & & -1.04685 & -0.082440 & 0.587 \\
\hline & & 0 & -0.894381 & 0.3004638 & 0.843 \\
\hline & & & -0.957630 & 0.1998305 & 0.767 \\
\hline & & & -0.999367 & 0.0988653 & 0.700 \\
\hline
\end{tabular}

Table 2.

\begin{tabular}{|c|c|c|c|c|c|}
\hline \multirow{3}{*}{$\operatorname{Pr}$} & \multicolumn{5}{|c|}{ Comparison of $-\theta^{\prime}(0)$ for different values Pr in the absence of the parameters } \\
& $\begin{array}{c}\text { Nadeem et al } \\
\text { [36] }\end{array}$ & $\begin{array}{c}\text { Khan and } \\
\text { Pop[37] }\end{array}$ & $\begin{array}{c}\text { Golra and } \\
\text { Sidawi } \\
{[38]}\end{array}$ & Wang [39] & Present study \\
\hline 0.7 & 0.454 & 0.454 & 0.454 & 0.454 & 0.454049257 \\
\hline 2.0 & 0.911 & 0.911 & 0.911 & 0.911 & 0.911360664 \\
\hline
\end{tabular}

Table 3.

\begin{tabular}{|c|c|c|c|c|c|}
\hline \multicolumn{6}{|c|}{$\begin{array}{l}\text { Comparison of }-f \text { " }(0) \text { for different values } \mathrm{M} \text { in the absence of the parameters } \mathrm{S}=\mathrm{R}=\mathrm{We}=\lambda=0 \text { and } \beta \\
\rightarrow \infty\end{array}$} \\
\hline $\mathrm{M}$ & $\begin{array}{l}\text { Anderson et } \\
\text { al.[40] }\end{array}$ & $\begin{array}{l}\text { Prasad et } \\
\text { al.[41] }\end{array}$ & $\begin{array}{l}\text { Mukhopadhyay et al. } \\
{[42]}\end{array}$ & $\begin{array}{l}\text { Palani et al } \\
{[35]}\end{array}$ & Present study \\
\hline 0.0 & 1.0000 & 1.000 & 1.000173 & 1.0000 & 1.00000 \\
\hline 0.5 & 1.2249 & 1.224 & 1.224753 & 1.2247 & 1.22474 \\
\hline 1 & 1.4140 & 1.414 & 1.414450 & 1.4142 & 1.41421 \\
\hline 1.5 & 1.5810 & 1.581 & 1.581140 & 1.5811 & 1.58113 \\
\hline 2 & 1.7320 & 1.732 & 1.732203 & 1.7320 & 1.73205 \\
\hline
\end{tabular}

Table 2 and 3 shows the comparison of the present results with the existed results of Palani et al. [35], Nadeem et al. [36], Khan et al. [37], Golra et al. [38], Wang [39], Anderson et al. [40], Prasad et al. [41], Mukhopadhyay et al. [42] and Sandeep et al. [43]. Under the same conditions, present results have an excellent agreement with the existed results. This shows the validity of the present results along with the accuracy of the numerical technique we have used in this study. Table 1 shows the impact of various parameters on the skin friction coefficient, local Nusselt number and local Sherwood number with two different boundary conditions. Increases the value of magnetic field parameter, porosity parameter and inclined magnetic field angle, reduce the value of $C_{f}, N u_{x}$ and $S h$ with both suction and melting surface.

\section{CONCLUSION}

We have investigated the influence of two different boundary conditions such as a melting surface and a porous surface for inclined MHD Casson fluid flow with higher order chemical reaction, variable radiation and heat source. We consider the first and second order velocity slip, temperature slip and mass slip. The conclusions of the present study are shown as follows:

1) The $\theta$ and $\phi$ profiles were uplifted with the increment of the $\beta, \mathrm{M}$ and $\mathrm{Kp}$ parameters on a suction and melting surface whereas the opposite behavior observed on $f$ ' profiles.

2) The $f^{\prime}$ profile and momentum boundary layer thickness was depressed with the increment of the $L_{1}$ and $L_{2}$ parameters under a suction and a melting surface whereas the reverse behavior observed on $\theta$ and $\phi$ profiles.

3) The $\theta$ profile and its related thermal boundary layer thickness were depreciating function of the $\delta_{1}$ and $\operatorname{Pr}$ on a suction surface and a melting surface.

4) The $\theta$ profile and its related thermal boundary layer thickness were rising function of the R, $\mathrm{A}^{*}$ and $\theta_{w}$ parameters on a suction surface and a melting surface.

5) Increment in $\delta_{2}, \mathrm{Kn}$ and Sc parameter suppresses $\phi$ profile on a suction surface and a melting surface.

6) The impact of various physical parameters on melting surface and porous surface are obtained and observed that the effect of melting surface is higher than porous surface.

\section{REFERENCES}

[1] Animasaun IL. (2015). Effects of thermophoresis, variable viscosity and thermal conductivity on free convective heat and mass transfer of non-darcian MHD dissipative Casson fluid flow with suction and $\mathrm{n}^{\text {th }}$ order of chemical reaction. Journal of the Nigerian Mathematical Society 34: 11-31.

[2] Megaheda AM. (2015). MHD viscous Casson fluid flow and heat transfer with second-order slip velocity and thermal slip over a permeable stretching sheet in the presence of internal heat generation/absorption and thermal radiation. Eur. Phys. J. Plus 130: 81.

[3] Bala P, Reddy A. (2016). Magneto hydrodynamic flow of a Casson fluid over an exponentially inclined permeable stretching surface with thermal radiation and 
chemical reaction. Ain Shams Engineering Journal 7: 593-602.

[4] Haq RU, Nadeem S, Akbar NS, Khan ZH. (2013). MHD three dimensional Casson fluid flow past a porous linearly stretching sheet. Alexandria Eng. J. 52(4): $577-$ 582. http://dx.doi.org/10.1016/j.aej.2013.08.005

[5] Hari RK, Harshad RP. (2016). Soret and heat generation effects on MHD Casson fluid flow past an oscillating vertical plate embedded through porous medium. Alexandria Engineering Journal 55: 2125-2137.

[6] Haq RU, Nadeem S, Lee C. (2012). MHD flow of a Casson fluid over an exponentially shrinking sheet. Sci. Iran. 19: 1550-1553.

[7] Mukhopadhyaya S, Moindala IC, Hayat T. (2014). MHD boundary layer flow of Casson fluid passing through an exponentially stretching permeable surface with thermal radiation. Chin. Phys. 23: 104701.

[8] Sandeep N, Raju CSK, Saleem S. (2016). Effects of induced magnetic field and homogeneousheterogeneous reactions on stagnation flow of a Casson fluid. Engineering Science and Technology, an International Journal 19: 875-887.

[9] Sandeep N, Raju CSK, Sugunamma V, Babu MJ, Reddy JVR. (2015). Heat and mass transfer in magnetohydrodynamic Casson fluid over an exponentially permeable stretching surface. Eng. Sci. Technol. Int. J. 19(1): 45-52. http://dx.doi.org/10.1016/j.jestch.2015.05.010

[10] Jain S, Parmar A. (2017). Comparative study of flow and heat transfer behavior of Newtonian and non-Newtonian fluids over a permeable stretching surface. Global and stochastic analysis, SI. pp. 41-50.

[11] Jain S, Parmar A. (2017). Study of radiative heat transfer of nano-Williamson fluid flow through a porous medium. Acta Technica 62(2):137-150.

[12] Jain S. (2006). Temperature distribution in a viscous fluid flow through a channel bounded by a porous medium and a stretching sheet. J. Rajasthan Acad. Phy. Sci. 4: 477-482.

[13] Jain S, Choudhary R. (2015). Effects of MHD on boundary layer flow in porous medium due to exponentially shrinking sheet with slip. Procedia Engineering 127: 1203-1210.

[14] Jain S, Choudhary R. (2017). Combined Effects of sunction/injection on MHD boundary Layer flow of nanofluid over horizontal permeable cylinder with radiation. Journal of advanced research in Dynamical and Control System 11: 88-98.

[15] Jain S, Bohra S. (2017). Heat and mass transfer over a three-dimensional inclined non-linear stretching sheet with convective boundary conditions. Indian Journal of Pure and Applied Physics 55: 847-856.

[16] Chauhan DS, Vyas P. (1995). Heat transfer in hydromagnetic couette flow of compressible Newtonian fluid. J. of Engng. Mech; ASCE 121(1): 57-61.

[17] Chauhan DS, Gupta S. (1999). Heat transfer in couette flow of a compressible Newtonian fluid through a channel with highly permeable layer at the bottom. AMSE periodicals: Mod. Meas.\& Contl. B. 67(2): 37-52.

[18] Parmar A. (2017). MHD Falkner-Skan flow of Casson fluid and heat transfer with variable property past a moving wedge. International Journal of Applied and Computational Mathematics 3(1): 611-629. http://dx.doi.org/10.1007/s40819-017-0373-x
[19] Parmar A. (2017). Unsteady convective boundary layer flow for MHD Williamson fluid over an inclined porous stretching sheet with non-linear radiation and heat source. International Journal of Applied and Computational $\begin{array}{lll}\text { Mathematics } & 3(1) \text { : 859-881. }\end{array}$ http://dx.doi.org/10.1007/s40819-017-0373-4

[20] Sandeep N, Sulochana C, Ashwinkumar GP. (2016). Similarity solution of 3D Casson nanofluid flow over a stretching sheet with convective boundary conditions. Journal of the Nigerian Mathematical Society 35: 128141.

[21] Bhattacharyya K, Uddin MS, Layek GC. (2016). Exact solution for thermal boundary layer in Casson fluid flow over permeable shrinking sheet with variable wall temperature and thermal radiation. Alexandria Engineering Journal 55: 1703-1712.

[22] Mukhopadhyay S. (2013). Casson fluid flow and heat transfer over a nonlinearly stretching surface. Chin Phys. 22: 7 .

[23] Bhattacharya K. (2013). Boundary layer stagnation point flow of Casson fluid and heat transfer towards a shrinking/stretching sheet. Front Heat Mass Transfer 4: 1-9.

[24] Animasaun IL, Adebile EA, Fagbade AI. (2016). Casson fluid flow with variable thermo-physical property along exponentially stretching sheet with suction and exponentially decaying internal heat generation using the homotopy analysis method. J. of the Nigerian Mathematical Society 35: 1-17.

[25] Animasaun IL, Sandeep N, Koriko OK. (2016). modified kinematic viscosity model for 3D-Casson fluid flow within boundary layer formed on a surface at absolute zero. J. Mol. Liq. 221: 1197-1206. http:// dx.doi.org/10.1016/j.molliq.2016.06.049

[26] Hayat T, Shehzad SA, Alsaedi A. (2016). Threedimensional MHD flow of Casson fluid in porous medium with heat generation. J. Appl. Fluid Mech. 9: 215-223.

[27] Hayat T, Ashraf MB, Shehzad SA, Alsaedi A. (2015). Mixed convection flow of Casson nanofluid over a stretching sheet with convectively heated chemical reaction and heat source/sink. J. Appl. Fluid Mech. 8: 803-813.

[28] Makinde OD, Ibrahim W. (2016). Magnetohydrodynamic stagnation point flow and heat transfer of Casson nanofluid past a stretching sheet with slip and convective boundary condition. J. Aerosp. Eng., 29(2): 04015037

[29] Makinde OD. (2012). Computational modelling of MHD unsteady Flow and heat transfer over a flat plate with Navier slip and Newtonian heating. Braz J Chem Eng. 29(1): 159-66.

[30] Daba M, Devaraj P. (2016). Unsteady hydromagnetic chemically reacting mixed convection flow over a permeable stretching surface with slip and thermal radiation. Journal of the Nigerian Mathematical Society. 35: 245-256.

[31] Nadeem S, Mehmood R, Akbar NS. (2015). Partial slip effect on non-aligned stagnation point nanofluid over a stretching convective surface. Chin. Phys. B 24(1): 1-8.

[32] Ramesh K, Devakar M. (2015). Some analytical solutions for flows of Casson fluid with slip boundary conditions. Ain Shams Eng. J. 6: 967-975.

[33] Ibrahim W, Shanker B. (2014). Unsteady MHD mixed 
convective boundary layer slip flow and heat transfer with thermal radiation and viscous dissipation. Heat Transfer - Asian Res. 43(5): 412-26.

[34] Krishnamurthya MR, Prasannakumara BC, Gireesh BJ, Reddy RS. (2016). Effect of chemical reaction on MHD boundary layer flow and melting heat transfer of Williamson Nano fluid in porous medium. Eng. Science and Technology, an Int J. 19: 53-61 2.

[35] Palani S, Kumar BR, Kameswaran PK. (2016). Unsteady MHD flow of an UCM fluid over a stretching surface with higher order chemical reaction. Ain Shams Engg J. 7: 399-408

[36] Nadeem S, Hussain ST. (2014). Flow and heat transfer analysis of Williamson Nanofluid. Appl Nanosci. 4(8): 1005-1012.

[37] Khan WA, Pop I. (2010). Boundary-layer flow of a Nanofluid past a stretching sheet. Int. J. Heat Mass Transf. 53: 2477-2483.

[38] Gorla RSR., Sidawi I. (1994). Free convection on a vertical stretching surface with suction and blowing. Appl. Sci Res. 52: 247-257.

[39] Wang Y. (1989). Free convection on a vertical stretching surface. J. Appl. Math Mech. 69: 418-420.

[40] Andersson HI, Hansen OR, Holmedal B. (1994). Diffusion of a chemically reactive species from a stretching sheet. Int. J. Heat Mass Trans. 37: 659-64.

[41] Prasad KV, Sujatha A, Vajravelu K., Pop I. (2012). MHD flow and heat transfer of a UCM fluid over a stretching surface with variable thermos-physical properties. Meccanica 47: 1425-39.

[42] Mukhopadhyay S, Golam AM, Wazed AP (2013). Effects of transpiration on unsteady MHD flow of an UCM fluid passing through a stretching surface in the presence of a first order chemical reaction. Chin Phys B. 22: 124701.

[43] Sandeep N, Krishna PM, Reddy JVR, Sugunamma. V. (2016). Dual solutions for unsteady flow of PowellEyring fluid past an inclined stretching sheet. J. of Naval Architecture and Marine Eng. 13: 89-99.

[44] Rajani D, Hemalatha K, Madhavi MVDNS. (2017). Effects of higher order chemical reactions and slip boundary conditions on nanofluid flow. Int. J. of Eng. Res. and Application 7(5): 36-45

[45] Rahman MM, Al-Lawatia M. (2010). Effects of higher order chemical reaction on micropolar fluid flow on a power law permeable stretched sheet with variable concentration in a porous medium. The Canadian J. of $\begin{array}{lll}\text { Chemical } & \text { Eng. } & \text { 88(1): }\end{array}$ http://dx.doi.org/10.1002/cjce.20244

[46] Mallikarjuna B, Bhuvanavijaya R. (2013). Effect of higher order chemical reaction on MHD non-Darcy convective heat and mass transfer over a vertical plate in a rotating system embedded in a fluid saturated porous medium with non-uniform heat source/sink. Proceedings of the 22th National and 11th International ISHMTASME Heat and Mass Transfer Conference, pp. 28-31.

[47] Sharma BR, Borgohain D. (2014). Influence of the order of chemical reaction and soret effect on mass transfer of a binary fluid mixture in porous media. Int. J. of Innovative Res. in Sci., Eng. and Technology 3: 7.

[48] Arifuzzaman SM, Rana BMJ, Ahmed R, Ahmmed F. (2017). Cross diffusion and MHD effects on a high order chemically reactive micropolar fluid of naturally convective heat and mass transfer past through an infinite vertical porous medium with a constant heat sink. AIP Conference Proceedings 1851: 020006. https://doi.org/10.1063/1.4984635

[49] Raju CSK, Kumar RVMSSK, Varma SVK., Madak AG, Prasad PD. (2017). Transpiration effects on MHD flow over a stretched cylinder with Cattaneo-Christov heat flux with suction or injection. Arabian J. for Science and Eng. 1-8.

[50] Raju CSK, Priyadarshini P, Ibrahim SM. (2017). Multiple slip and cross diffusion on MHD CarreauCasson fluid over a slandering sheet with non-uniform heat source/sink. Int. J. of Applied and Computational Mathematics 3(1): 203-224.

[51] Sivakumar N, Prasad DP, Raju CSK, Varma SVK, Shehzad SA. (2017). Partial slip and dissipation on MHD radiative ferro-fluid over a non-linear permeable convectively heated stretching sheet. Results in Physics 7: 1940-1949.

\section{NOMENCLATURE}

\begin{tabular}{|c|c|}
\hline$u(x, y)$ and $v(x, y)$ & $\begin{array}{l}\text { Horizontal and vertical velocity } \\
\text { components, } \\
\text { fluid density, }\end{array}$ \\
\hline$\rho \mathrm{C}_{\mathrm{p}}$ & $\begin{array}{l}\text { kinematic viscosity, } \\
\text { particles heat capacities. }\end{array}$ \\
\hline $\begin{array}{l}\mathrm{T} \\
T_{\infty} \\
b\end{array}$ & $\begin{array}{l}\text { fluid temperature, } \\
\text { ambient fluid temperature, } \\
\text { positive constant. }\end{array}$ \\
\hline $\operatorname{Pr}=\frac{k}{\mu C_{p}}$ & Prandtl number, \\
\hline$R=\frac{4 \sigma T_{\infty}^{3}}{k k^{*}}$ & radiation parameter, \\
\hline$k^{*}$ & thermal radiation parameter, \\
\hline$E c=U^{2} / C_{p}\left(T_{W}-T_{\infty}\right)$ & Eckert number \\
\hline$M=\frac{\sigma B_{0}^{2}}{\rho b}$ & magnetic field parameter, \\
\hline$\beta$ & Casson fluid parameter, \\
\hline$S c=\frac{v}{D_{m}}$ & Schmidt number, \\
\hline$c_{s}$ & $\begin{array}{l}\text { the heat capacity of the solid } \\
\text { surface }\end{array}$ \\
\hline$K_{n}=\frac{k_{n}}{b}\left(C_{w}-C_{\infty}\right)^{n-1}$ & chemical reaction parameter, \\
\hline$\beta_{m}$ & the latent heat of the fluid, \\
\hline$\varepsilon=\frac{T_{w}}{T_{\infty}}$ & temperature difference parameter, \\
\hline$k$ & thermal conductivity \\
\hline$K p=\frac{v}{k_{p} b}$ & porosity parameter, \\
\hline$M e=\frac{\left(T_{w}-T_{\infty}\right) \mathrm{c}_{p}}{\left(\beta_{m}+\mathrm{c}_{s}\left(T_{m}-T_{0}\right)\right)}$ & dimensionless melting parameter \\
\hline
\end{tabular}

